J. Environ. Sci.

Institute of Environmental Studies and Research - Ain Shams University

\title{
EFFECT OF SOME INSECTICIDES ON RESISTANCE LEVEL AND CERTAIN BIOCHEMICAL ASPECTS IN Ceratitis Capitata (DIPTERA: TEPHRITIDEA) FROM DIFFERENT LOCALITIES IN EGYPT
}

\section{Rasha S. Abou-El-Fotouh(1); Kadry W. Mahmoud ${ }^{(2)}$; \\ Ahmed M. Z. Mosallam ${ }^{(1)}$ and Nazmi A. Abdel Ghani ${ }^{(3)}$}

1) Plant Protection Research Institute, Agric. Res. Center 2) Plant Protection Dep., Faculty of Agric., Ain Shams Univ. 3) Horticulture Dep., Faculty of Agric., Ain Shams University

\begin{abstract}
To estimate toxic actions of two insecticides on \{lambda-cyhalothrin (Karilot gold 5\%EC) and the biopesticide spinosad, (Conserve 0.24\%CB) \}, adults of the laboratory strain of Mediterranean fruit fly, Ceratitis capitata (Wied.) were treated with different concentrations. Discriminating value (LC99) was selected for monitoring resistance in three field populations collected from different governorates (Qaluobia, Behira and Sharkia). Data showed that, males of laboratory strain as well as field colony strains were more susceptible than females. Qaluobia field colony exhibited the highest resistance level to lambda-cyhalothrin followed by Sharkia and Behira colonies in both male and female flies comparing with laboratory strain. Sharkia colony showed remarkable higher level of resistance to spinosad in males and females more than Behira and Qaluobia colonies. On the other hand, Ceratitis capitata flies of the different field strains showed remarked higher levels of the enzymes activity than the laboratory strain. Males showed the highest levels of acid phosphatase in Qaluobia, whereas Sharkia showed the highest level in females. The levels of alkaline phosphatase were higher in Qaluobia followed by Behira and Sharkia in both sexes. Behira had the highest enzymatic activity of AChE in male and female flies. The levels of total protein were higher in Behira than the other field colonies in males, but Sharkia exhibited the highest level in case of female flies.
\end{abstract}


This means that the enzymatic activities play an important role in the insect resistance to spinosad and lambda-cyhalothrin, and there were positive correllation between resistance levels and enzymatic activity in the different field colonies.

Keywords: Mediterranean fruit fly, Ceratitis capitata, Pesticides, Biopesticides, Resistance, Discriminating, Biochemical, lambda-cyhalothrin, spinosad.

\section{INTRODUCTION}

The Mediterranean fruit fly, Ceratitis capitata (Wiedemann) is one of the most harmful pest in order Diptera: Tephiritidea. It is the most widespread in many countries all over the world and considers one of the most dangerous insect pests for horticultural crops (White \& Elson-Harris, 1992 and Solari et al., 2016). This cosmopolitan and polyphagous species of fruit flies invades about 350 hosts such as apple, apricot, citrus, figs, guava, mangoes, peach, pear, quince and others (White and Elson-Harris, 1992). Females deposit eggs under the peel of semi-ripening and ripening fleshy fruits. The hatched larvae feed on the pulp of the infested fruits causing deleterious damage throughout 3 larval instars. After that, the full grown larvae ( $3^{\text {rd }}$ larval instar) leave the fallen fruits to pupate inside soil at 2-5 cm depth. Under Egyptian conditions, the Mediterranean fruit fly have about 8 - 10 generations (Hafez and Fares, 1967).It causes losses directly and indirectly in the crops, resulting in significantly low productivity per feddan as well as reducing fruit quality (Joomaye et al., 2000).

Some chemical insecticides which belong to different groups have been used to control this harmful insect. These insecticides had side effects on the environment, human health and had toxic effects on non-target organisms The wide-spread use of chemical pesticides causes adverse effects on pest. 
Because of excessive repeated use resulting in create of resistance strains of pests and thus disrupt the ecological balance, The existence of resistant strains to pesticides will have an impact in increasing the use of such pesticides with high concentrations or rates. The use of a high concentration of pesticide had negative impact on the natural enemies and the ecosystem, rising pesticides residues in fruits, leading to increase costs for farmers and rejected fruit export shipments (Carante and Lemaitre, 1980; Rossi \& Rainaldi, 2000 and Magana et al., 2007).

This work aimed to estimate, in laboratory experiments, the resistance of certain insecticides (Spinosad and Lambda-Cyhalothrine) against the adults of $C$. capitata (Wied.) of three field strains (Qaluobia, Behira and Sharkia) compared to the laboratory strain.

\section{MATERIAL AND METHODS}

\section{1- Rearing Technique}

1-1-Laboratory strain: Laboratory strain of $C$. capitata were continuously reared under laboratory conditions of $25 \pm 3{ }^{\circ} \mathrm{C}$ and $60 \pm 5 \%$ R.H in Horticulture Insects Research Department, Plant Protection Research Institute, Agricultural Research Center, Dokki, Giza, Egypt. Adults of $C$. capitata were reared in a cage $(60 \times 40 \times 40 \mathrm{~cm})$ with wooden frames and covered from each side with metal screen, except one side that covered with muslin clothes for oviposition. Flies in rearing cage were fed with sugar and fortified protein hydrolysate at ratio of 5:1, respectively. Also, water was added in a plastic bottle with cotton plug. Eggs were received 
in plastic pans filled with $3 \mathrm{~cm}$ water to prevent eggs dehydration (Awadallah and El-Hakim, 1987).

1-2-Field strains: To obtain mass production, large quantities of infested Guava fruits were collected from heavily infested orchards in the three examined governorate (Qaluobia, Sharkia and Behira). These fruits were separately incubated in large plastic pans with fine sand to allow jumping larvae to pupate. Pupae of each strain were separated via sieving and introduce to separate cages for each strain. Adults of these strains were dealt or processed as the laboratory strain.

1-3- Larval diet content: The larval artificial diet consists of tap water (500 $\mathrm{ml})$, wheat bran $(330 \mathrm{gm})$, sugar $(84.50 \mathrm{gm})$, Brewer's yeast $(84.50 \mathrm{gm})$, sodium benzoate $(3.00 \mathrm{gm})$ and citric acid $(3.00 \mathrm{gm})$.These ingredients were carefully mixed in large plastic container. Then, eggs were scattered on the surface of the diet which was placed in plastic trays of $20 \times 10 \times 8 \mathrm{~cm}$ that were tightly covered with muslin clothes using rubber bands. After that, these trays were placed in large plastic pans with sand at the bottom to allow the jumping larvae to pupate. All pupae were separated by sieving from sand (Awadallah and El-Hakim, 1987).

\section{2- Pesticides Used:}

1- Karilot gold 5\% EC (Lambda-Cyhalothrin).

2- Conserve $0.24 \%$ CB (Spinosad).

3- Method of Application: A discriminating concentration technique was used for rapid monitoring insecticidal resistance in field-collected, Ceratitis capitata flies. Roush and Miller (1986) revealed that testing an insect sample at a discriminating concentration is more efficient than 
estimating dose-response regression lines in monitoring for resistance. The diagnostic concentration is a single concentration that can discriminate between susceptible and resistant individuals. Gunning et al. (1984) suggested that the discriminating concentration was the $\mathrm{LC}_{99}$ values for susceptible insects. The $\mathrm{LC}_{99}$ of the susceptible $C$. capitata flies were estimated previously from the adult via technique by probit analysis and used to estimate a diagnostic concentration for the two compounds tested, based on considerations of Roush and Miller (1986). To estimate a concentration that would reliably discriminated, sixty males and 60 females were separately placed in small cages in three replicates (10 pairs / each cage) that were exposed to Petri-dishes treated with the tested insecticides. Two ml. of each compound was pipetted into a Petri-dish. Petri-dishes were rolled for approximately $2 \mathrm{~min}$. to ensure that all surfaces received the insecticidal treatment. Petri-dishes were air dried (vertically) at room temperature for 24 hours. Cages with flies were placed at room temperature, and the mortality was assessed after 24 hours.

Resistance percentages in the tested insecticide in the field colonies were determined by calculating mortality percentage of the discriminating concentration of Spinosad and Lambda-Cyhalothrin, the correcting control mortality and percentage of survival in laboratory insect at the discriminating concentration used. To calculate the resistance percentage, the following formula adopted by McCutchen et al. (1989) was used.

Resistance percentage $=100-(\mathrm{MF} / \mathrm{MSx} 100)$, where:

$\mathrm{MF}=\%$ mortality at discriminating concentration in field collected flies. 
$\mathrm{MS}=\%$ mortality (constant) at discriminating concentration in laboratory flies.

\section{4- Biochemical Assays}

4.1. Determination of total proteins activity: Total proteins were determined by method of Bradford (I976). Protein reagent was prepared by dissolving 100mg of Coomassie Brilliant blue G-250 in 50ml 95\% ethanol. To this solution $100 \mathrm{ml} 85 \%(\mathrm{~W} / \mathrm{V})$ phosphoric acid were added. The resulting solution was diluted to a final volume of 1 liter.

4.2. Determination of acid and akaline phosphatase activity: Acid and alkaline phosphatases were determined according to the method described by Powell and Smith (1954). In this method, the phenol released by enzymatic hydrolysis of disodium phenylphosphate reacts with 4-aminoantipyrine and by the addition of potassium ferricyanide, the characteristic brown color is produced.

4.3. Determination of acetylcholine esterase activity: AChE (acetylcholine esterase) activity was measured according to the method described by Simpson et al. (1964), using acetylcholine bromide (AchBr) as substrate.

\section{RESULTS AND DISCUSSION}

1- Mortality Percentages: Data in Table (1) indicate effectiveness of the different concentration of the two used pesticides (Spinosad and LambdaCyhalothrin) against males and females of $C$. capitata laboratory strain. The tested concentrations ranged between 2500- 12500 and 25- 200 ppm for Spinosad and Lambda Cyhalothrin, respectively. The mortality percentages ranged between 21.40-94.23, 21.00- 83.73\% (for Spinosad) 
and 15.95- 83.05\%, 12.54- 78.88\% (for Lambda Cyhalothrin) for males and females, respectively. The slope values of Spinosad were 2.22 and 2.16 for males and females, whereas those obtained for the second pesticide (Lambda Cyhalothrin) were 3.08 and 2.43 for males and females, consecutively. The values of $\mathrm{LC}_{50}$ for males and females were 5420.42, 5952.90 and 94.14, 92.31 ppm for Spinosad and Lambda-Cyhalothrin, respectively. But, the respective LC $99_{99}$ were 30549.21, 53249.61 and 1042.73, 1094.39 ppm.

Table (1): Efficiency of two pesticides against males and females of $C$. capitata laboratory strain

\begin{tabular}{|c|c|c|c|c|c||}
\cline { 2 - 6 } \multicolumn{1}{c|}{} & \multicolumn{3}{c|}{ Lambda-Cyhalothrin } & \multicolumn{2}{c|}{ Spinosad } \\
\hline \multicolumn{2}{|c|}{ Mortality (\%) } & $\begin{array}{c}\text { Concentration } \\
(\mathbf{p p m})\end{array}$ & \multicolumn{2}{c|}{ Mortality (\%) } & $\begin{array}{c}\text { Concentration } \\
(\mathbf{p p m})\end{array}$ \\
\hline Female & Male & & Female & Male & \\
\hline 78.88 & 83.05 & 200 & 83.73 & 94.23 & 12500 \\
\hline 67.29 & 69.42 & 150 & 68.51 & 73.99 & 10000 \\
\hline 46.36 & 46.07 & 100 & 54.25 & 55.46 & 7500 \\
\hline 34.43 & 34.20 & 75 & 38.77 & 37.18 & 5000 \\
\hline 25.30 & 20.29 & 50 & 21.00 & 21.40 & 2500 \\
\hline 12.54 & 15.95 & 25 & - & - & - \\
\hline 2.43 & 3.08 & Slope & 2.16 & 2.22 & Slope \\
\hline 92.31 & 94.14 & LC 50 & 5952.90 & 5420.42 & LC $_{50}$ \\
\hline 1094.39 & 1042.73 & LC 99 & 53249.61 & 30549.2 & LC 99 \\
\hline
\end{tabular}


2- Resistance Percentages: Mortality and resistance percentages as well as relative resistance formales and females of three different field collections (Qaluobia, Behira and Sharkia) to discriminating concentrations of the two used pesticides were shown in Table (2). The percentages of mortality for males and females of the three examined field colonies ranged between $29.41-40.74 \%, 6.66-34.61 \%$ and $0.0-28.57 \%, 0.0-$ $21.05 \%$ for Spinosad and Lambda-Cyhalothrin, respectively. The discriminating concentration ( $\mathrm{LC}_{99}$ ) of the baseline caused 59.59, 58.84 and $70.29 \%$ resistance to spinosad for males collected from Qaluobia, Behira and Sharkia, respectively. Males of Sharkia field colony exhibited the highest values of resistance to Spinosad (70.29\%). Females of the three tested field colonies showed differently values of \% resistance to Spinosad of 79.79, 65.04 and 93.27 for Qaluobia, Behira and Sharkia, respectively. The relative resistance of the three tested field colonies to spinosad ranged between 1- 1.18 and 1- $1.43 \%$ for males and females, successively. 
J. Environ. Sci.

Institute of Environmental Studies and Research - Ain Shams University

Table (2): Response of males and females of $C$. capitata collected from three governorates to discriminating concentrations of pesticides

\begin{tabular}{|c|c|c|c|c|c|c|c|}
\hline \multirow{2}{*}{ Pesticide } & \multirow{2}{*}{ Strain } & \multicolumn{2}{|c|}{$\begin{array}{c}\text { Mortality } \\
(\%)\end{array}$} & \multicolumn{2}{c|}{$\begin{array}{c}\text { Resistance } \\
(\%)\end{array}$} & \multicolumn{2}{c|}{$\begin{array}{c}\text { Relative } \\
\text { resistance }\end{array}$} \\
\cline { 3 - 8 } & & Male & Female & Male & Female & Male & Female \\
\hline \multirow{2}{*}{$\begin{array}{c}\text { Spinosad } \\
(\text { Conserve })\end{array}$} & Qaluobia & 40 & 20 & 59.59 & 79.79 & 1.17 & 1.16 \\
\cline { 2 - 8 } & Behira & 40.74 & 34.61 & 58.84 & 65.04 & 1.18 & 1.43 \\
\cline { 2 - 8 } & Sharkia & 29.41 & 6.66 & 70.29 & 93.27 & 1 & 1 \\
\hline $\begin{array}{c}\text { Lambda } \\
\text { Cyhalothrin } \\
(\text { Karilot })\end{array}$ & Qaluobia & 0 & 0 & 100 & 100 & 1 & 1 \\
\cline { 2 - 8 } & Behira & 28.57 & 21.05 & 71.14 & 78.73 & 1.40 & 1.27 \\
\cline { 2 - 8 } & Sharkia & 25 & 10 & 74.74 & 89.89 & 1.33 & 1.11 \\
\hline \hline
\end{tabular}

${ }^{*}$ Resistance $=100-\frac{\$ \text { mortality at discriminating concentration in field strain }}{\text { mortality at discriminating concentration in labortory strain }} \times 100$

$* *$ Relative resistance $=\frac{\text { The highest resistance percentage }}{\text { corresponding resistance percentage of each strain }}$

Respecting the second compound (Lambda-Cyhalothrin.) according to the discriminating concentration ( $\mathrm{LC}_{99}$ ), Qaluobia field colony showed the highest values of \% resistance (100) for each males and females. The other tested field colonies (Sharkia and Behira) recorded \% resistance to LambdaCyhalothrin of 74.74, 71.14 and $89.89,78.73$ for males and females of $C$. capitata, respectively. The resistance relatively ranged between 1-1.40 and 11.27 for males and females, consecutively.

3- Effect on Acid Phosphatase: Statistical analysis of variance of data revealed that the differences in amounts of acid phosphatase between the examined colonies were highly significant in both males and females of the Mediterranean fruit fly (Table 3). The amounts of acid phosphatase insignificantly varied in males of the three examined field colonies and 
higher than that of laboratory strain. The highest amount of acid phosphatase (29.07 mU/g.b.w.) was shown in males of Qaluobia field colony followed by Behira and Sharkia field colonies (28.50 and 26.90 $\mathrm{mU}$ /g.b.w., respectively) in case of females, the highest

Table (3): Acid phosphatase activity in the whole homogenates of different field colony of Ceratitis capitata compared to the laboratory strain.

\begin{tabular}{|c|c|c|c|c|}
\hline \multirow{2}{*}{ Field colony } & \multicolumn{2}{|c|}{ (mU/ g.b.wt) Acid phosphatase } & \multicolumn{2}{c|}{ Activity ratio } \\
\cline { 2 - 5 } & $\sigma^{\lambda}$ & $q$ & $\sigma^{\lambda}$ & + \\
\hline \hline Qaluobia & $29.07 \pm 0.95^{\mathrm{a}}$ & $23.1 \pm 0.95^{\mathrm{b}}$ & 1.36 & 1.11 \\
\hline Behira & $28.5 \pm 1.37^{\mathrm{a}}$ & $20.83 \pm 0.25^{\mathrm{c}}$ & 1.33 & 1.003 \\
\hline Sharkia & $26.9 \pm 1.77^{\mathrm{a}}$ & $33.9 \pm 1.28^{\mathrm{a}}$ & 1.26 & 1.63 \\
\hline Laboratory & $21.43 \pm 0.60^{\mathrm{b}}$ & $20.77 \pm 0.57^{\mathrm{c}}$ & 1 & 1 \\
\hline F test & $23.17^{* *}$ & $160.75^{* *}$ & - & - \\
\hline L.S.D & 2.36 & 1.61 & - & - \\
\hline
\end{tabular}

* Enzymatic activity was expressed as $\mu$ g naphthol released / min / g.b.w.

** Activity ratio = enzymatic activity of filed colony strain/ enzymatic activity of the laboratory strain

Value of acid phosphatase amount (33.9 mU/g.b.w.) was significantly observed in individuals of Sharkia field colony. But, the lowest value of 20.83 mU/g.b.w. was recorded with females of Behira colony that insignificantly varied with those shown with females of laboratory colony (20.77 mU /g.b.w.). The activity ratios of the three tested field colonies were 1.36, 1.33, 1.26 fold (for males) and 1.11, 1.003, 1.63 fold (for females) of the laboratory colony. 
4- Effect on Alkaline Phosphatase: As shown in Table (4) the differences in Alkaline phosphatase between the examined colonies were statistically high significant. Qaluobia field colony significantly recorded the highest amounts of Alkaline phosphatase in both males and females (932.67 and $1074.33 \mathrm{mU} /$ g.b.wt) showing the highest values of activity ratio 3.63 and 5.63fold of laboratory colony, respectively. The amounts of Alkaline phosphatase in males and females of both Behira and Sharkia colonies were insignificantly differed (603.33, 463.0 and 553.67, $430.67 \mathrm{mU} /$ g.b.wt., respectively. The respective activity ratios were 2.35, 2.43 and 2.15, 2.25 fold of laboratory colony, successively.

Table (4): Alkaline phosphatase activity in the whole homogenates of different field colony of Ceratitis capitata compared to the laboratory strain

\begin{tabular}{|c|c|c|c|c|}
\hline \multirow{2}{*}{ Field colony } & \multicolumn{2}{|c|}{ (mU/ g.b.wt) Alkaline phosphatase } & \multicolumn{2}{|c|}{ Activity ratio } \\
\hline & 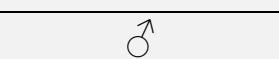 & q & $\pi$ & o \\
\hline Qaluobia & $932.67 \pm 39^{\mathrm{a}}$ & $1074.33 \pm 23.8^{\mathrm{a}}$ & 3.63 & 5.63 \\
\hline Behira & $603.33 \pm 25.17^{b}$ & $463 \pm 12.53^{b}$ & 2.35 & 2.43 \\
\hline Sharkia & $553.67 \pm 21.22^{b}$ & $430.67 \pm 43.14^{b}$ & 2.15 & 2.25 \\
\hline Laboratory & $256.67 \pm 15.27^{\mathrm{c}}$ & $190.67 \pm 9.02^{c}$ & 1 & 1 \\
\hline $\mathrm{F}$ test & $324.11 * *$ & $638.53 * *$ & - & - \\
\hline L.S.D & 50.16 & 48.61 & - & - \\
\hline
\end{tabular}

5- Effect on Acetylcholine Esterase: Amounts of acetylcholine esterase in males and females of the tested colonies high significantly differed (Table, 5). The highest amounts of enzyme (396.67 and 317.67 AchBr/min/g.b.w.) were shown with males and females of Behira field colony recording the 
highest ratios of activity of 1.23 and 1.61 fold of the laboratory colony. The activity ratios of males and females of the other two used colonies (Qaluobia and Sharkia) were 1.16, 1.60 and 1.14, 1.59 fold of the laboratory colony, successively.

Table (5): Acetylcholin esterase activity in the whole homogenates of different field colony of Ceratitis capitata compared to the laboratory strain

\begin{tabular}{|c|c|c|c|c|}
\hline \multirow{2}{*}{ Field colony } & \multicolumn{2}{|c|}{ ugAchBr/min/ g.b.wt (AchE) } & \multicolumn{2}{|c|}{ Activity ratio } \\
\cline { 2 - 5 } & $\delta^{\wedge}$ & + & $\oint^{\wedge}$ & + \\
\hline \hline Qaluobia & $374 \pm 5.29^{\mathrm{ab}}$ & $315.67 \pm 4.04^{\mathrm{a}}$ & 1.16 & 1.60 \\
\hline Behira & $396.67 \pm 15.27^{\mathrm{a}}$ & $317.67 \pm 5.86^{\mathrm{a}}$ & 1.23 & 1.61 \\
\hline Sharkia & $368.67 \pm 20.13^{\mathrm{b}}$ & $314.33 \pm 5.51^{\mathrm{a}}$ & 1.14 & 1.59 \\
\hline Laboratory & $323.33 \pm 7.64^{\mathrm{c}}$ & $197.33 \pm 6.43^{\mathrm{b}}$ & 1 & 1 \\
\hline F test & $15.62^{* *}$ & $344.87^{*} *$ & - & - \\
\hline L.S.D & 25.35 & 10.41 & - & - \\
\hline
\end{tabular}

6- Effect on Total Proteins: Data compiled in Table (6) reveal that the amounts of total proteins in males and females of the used colonies high significantly varied. Males of Behira colony significantly showed the highest amount of total proteins $(95.77 \mathrm{mg} / \mathrm{g.b} . \mathrm{wt})$ recording the highest value of activity ratio (1.19) that insignificantly differed with those obtained with Qaluobia colony (93.8 mg/ g.b.wt). The latest colony showed activity ratio of 1.17 fold of the laboratory one. The differences in amounts of total proteins in males of Sharkia colony $(87.63 \mathrm{mg} / \mathrm{g} . \mathrm{b} . \mathrm{wt})$ insignificantly varied with those of Qaluobia colony showing the lowest value of activity ratio of 1.09 fold of the laboratory one. But, females of 
Sharkia colony significantly recorded the highest amount of total proteins (97.23 mg/ g.b.wt.) showing the highest value of activity ratio of 1.49 fold of the laboratory colony. The other tested colonies of Qaluobia and Behira showed insignificantly and nearly equal amounts of total proteins of 80.47 and $83.90 \mathrm{mg} / \mathrm{g}$. b.wt, respectively. The respective activity ratios were 1.24 and 1.29 fold of the laboratory colony.

Table (6): Total proteins activity in the whole homogenates of different field colony of Ceratitis capitata compared to the laboratory strain.

\begin{tabular}{|c|c|c|c|c|}
\hline \multirow{2}{*}{ Field colony } & \multicolumn{2}{|c|}{ Total proteins (mg/ g.b.wt) } & \multicolumn{2}{|c|}{ Activity ratio } \\
\hline & $\hat{0}$ & 울 & $\hat{0}$ & $\underline{9}$ \\
\hline Qaluobia & $93.8 \pm 3.9^{\mathrm{ab}}$ & $80.47 \pm 1.6^{b}$ & 1.17 & 1.24 \\
\hline Behira & $95.77 \pm 2.96^{\mathrm{a}}$ & $83.9 \pm 1.34^{\mathrm{b}}$ & 1.19 & 1.29 \\
\hline Sharkia & $87.63 \pm 2.69^{b}$ & $97.23 \pm 2.42^{\mathrm{a}}$ & 1.09 & 1.49 \\
\hline Laboratory & $79.87 \pm 3.5^{c}$ & $64.87 \pm 1.9^{c}$ & 1 & 1 \\
\hline F test & $14.12 * *$ & $152.91 * *$ & - & - \\
\hline L.S.D & 6.22 & 3.51 & - & - \\
\hline
\end{tabular}

The results obtained in this investigation clear that there were significant differences between the response of male and female of Ceratitis capitata spinosad. Valtierra-de-Luis.et al. (2019) evaluated the toxicicty dose of Spinosad and determined the presence of resistance traits in Ceratitis capitata (Tephritidae) and Drosophila suzukii. The concentration-mortality response did not differ between the sexes or among three different batches of insects. Lethal dose values were calculated based on mean ingested volumes. For $C$. capitata $\mathrm{LD}_{50}$ values were 1.462 and 1.502 nga.i./insect for males and 
females, respectively, equivalent to 0.274 and 0.271 nga.i./mg for males and females of the second species of $D$. suzukii, respectively.

Data in the present study are accordance with those published by AbouElsoud. et al (2013). who monitored resistance in different field strains of Bactrocera zonata flies. The obtained results revealed that the discriminating concentration of the organophosphorus insecticide; Malathion ( $\mathrm{LC}_{99}$ ) caused $62.32,58.20,42.40$ and $40 \%$ mortality for the flies collected from Qaluobia, Behira, Menoufia and Ismailia governorates; respectively. Flies of Ismailia field colony exhibited the highest resistance value to Malathion toxicity. The corresponding resistance value was 59.60\%; whereas Qaluobia strain recorded the lowest resistance value to Malathion action (37.05\%). On the other hand, Behira and Menoufia governorates occupied the middle situation of resistance in this pest strain among the two strains that mentioned previously.

The results obtained in this study exhibited the same as Akl (2016). who found that males of Ceratitis capitata of laboratory strain as well as field colony strain were more susceptible than females and the mortality percent increased by increasing insecticide concentrations. The results indicated that female flies of all governorates were more resistant than male flies to the insecticides toxicity. Biochemical assays of AChE, $\alpha$ - esterases, acid and alkaline phosphatase activity level were remarkable much higher in both sexes' of the field colony than the corresponding levels in the laboratory strain.

The results obtained in this study agree with those found by Young et al (2005) who reported that pyrethriod resistance in field populations of 
Australian Helicoverpa armigera is primarily asquence of the overproduction of esterases isoenzymes which metabolite and sequester pyrethriods. Hassan and Mostafa (2000) studied the effect of DEF an esterases inhibitor, N-propyl paraoxon a phosphatases inhibitor on the toxicity of three organophosphorus insecticides namely Lebaycid, Malathion and Fenitrotion against the $3^{\text {rd }}$ instar larvae of $C$. capitate. They found that the synergistic rates were higher in the field colony as compared with the laboratory strain.

\section{REFERENCES}

Abu El-Seoud, Soad; Kidr, A. A; Mostafa, Z. K.; Zaky, A. M. and Akel, F .A. (2013): Monitoring resistance in different field strains of the peach fruit fly Bactrocera zonata (Saund.) to Malathion action in relation to biochemical aspects. Egypt. J. of Appl. Sci., 28 (10): 211-228.

Akl, F. A. (2016): Monitoring resistance in different field strains of the Mediterranean fruit fly, Ceratitis capitata (Wied.) to toxicity of the oregano phosphorus insecticide Malatox in relation to some enzymes activity. Egy. J. Plant Pro. Res., 4 (3): 39-57.

Awadallah, A. M. and El-Hakim, A. M. (1987): Methods for mass production of the Mediterranean fruit fly, Ceratitis capitates Wied. IIMethods for producing adults. Zagazig J. Agric. Res., 14(1): 709-719.

Bradford, M. M. (1976): A rapid and sensitive method for the quantitation of microgram quantities of proteins utilizing the principle of protein-dye binding. Anal. Biochem., 72:248-254.

Carante, J. P. and Lemaitre, C. (1980): Effect of selection for resistance to starvation on adult Ceratitis capitata (Diptera, Trypetidae). Annales de la Nutrition et de l'Alimentation, 34(3):547-564. 
Gunning, R. V.; Easton, C. S.; Greenup,L. R. and Edge, V. R. (1984). Pyrethroid resistance in Heliothis armigera in Australia. J.Econ. Entomol., 77: 1283-1287.

Hafez, M. and Fares, F. (1967): Annual number of generations of the Mediterranean fruit fly, Ceratitis capitata (Wied.) in U. A. R., Agric. Res. Rev., 45(2): 91-96.

Hassan, A. I. and Mostafa, A. M. (2000): Synergism the toxic action of some organophours insecticides against the Mediterranean fruit fly, Ceratitis capitata (Wied.) larvae. Egypt. J. Appl. Sci., 15(11): 334-345.

Joomaye, A. N.; Price, N. S. and Stonehouse, J. M. (2000): Quarantine pest risk analysis of fruit flies in Indian Ocean: Bactrocera zonata. Proceedings of the Indian Ocean Commission regional fruit fly Symposium. $5^{\text {th }}-9^{\text {th }}$ June, 2000: 179-183.

Magana, C.; Hernandez-Crespo, P.; Ortego, F. and Castanera, P. (2007): Resistance to malathion in field populations of Ceratitiscapitata. J. Econ. Entomol., 100(6): 1836-1843.

McCutchen, B. F.; Plapp, F.W.; Nemec, S. J. and Campanhola, C. (1989): Development of diagnostic monitoring techniques for larval pyrethroid resistance in Heliothis spp. (Lepidoptera: Noctuidae) in cotton. J.Econ. Entomol., 82(6): 1502-1507.

Powell, M. E. A. and Smith, M. J. H. (1954): The determination of serum acid and alkaline phosphatase activity with 4- aminoantipyrine .J. Clin. Pathol ., 7 : 245-248.

Rossi, E and Rainaldi, G. (2000): Induction of malathion resistance in CCE/CC128 cell line of Mediterranean fruit fly (Ceratitis capitata (Wied.)) (Diptera: Tephritidae). Cytotechnology, 34(1/2):11-15.

Roush, R. T. and Miller, G. L. (1986): Considerations for design of insecticide resistance monitoring programs .J. Econ. Entomol., 79:293-298. 
Simpson, D. R.; Bulland, D. L. and Linquist, D. A. (1964): A semimicrotechnique for estimation of cholinesterase activity in boll weevils. Ann. Ent. Soc. Amer., 57: 367-371.

Solari, P.; Corda, V.; Sollai, G.; Kreissl, S.; Galizia, C. G. and Crnjar, R. (2016): Morphological characterization of the antennal lobes in the Mediterranean fruit fly Ceratitis capitata. Journal of Comparative Physiology A: Neuroethology, Sensory, Neural, and Behavioral Physiology, 202(2):131-146.

Valtierra-de-Luis, D.; Villanueva, M.; Caballero, J.; Matas, I. M.; Williams, T. and Caballero, P. (2019) Quantification of dose-mortality responses in adult Diptera: validation using Ceratitis capitata and Drosophila suzukii responses to spinosad. PLoS One,. 14 (2): $\mathrm{e} 0210545$.

White, I. M. and Elson-Harris, M. M. (1992): Fruit flies of economic significance: Their identification and bionomics. C.A.B. International, Wallingford, UK, 601pp.

Young, S. J.; Gunning, R. V. and Moores, G. D. (2005): The effect of piperonylbutoxide on pyrethroid-resistance-associated esterases in Helicoverpa armigera (Hubner) (Lepidoptera: Noctuidae ). Pest Mang. Sci 61: 397-401. 


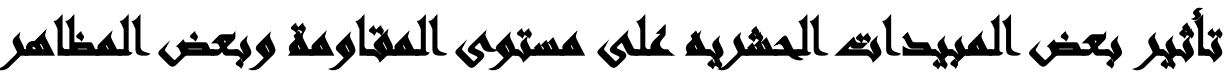

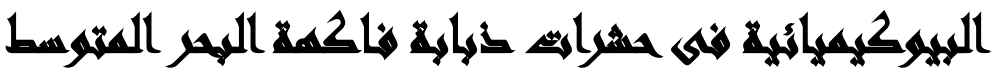

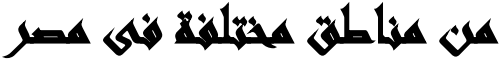

[؛]

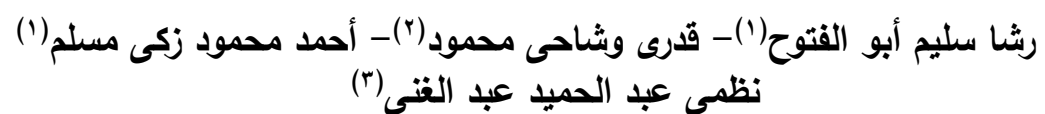

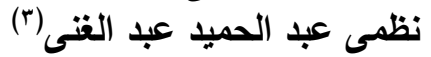

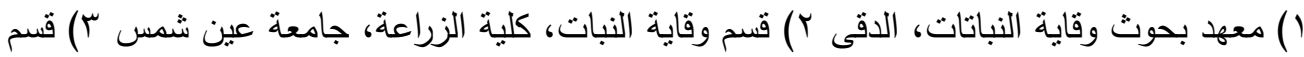

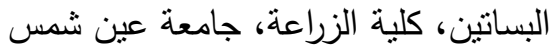

\section{المستطليك}

تم معاملة الأطوار الكاملة من السلالة المعملية لذبابة فاكهة البحر المتوسط لتركيزات مختلفة من

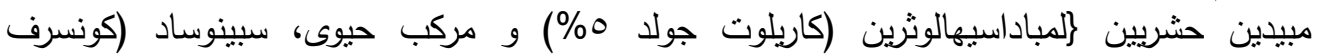

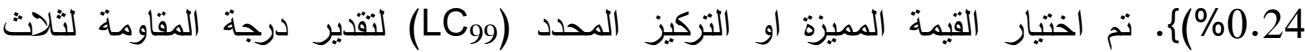
مجتمعات حقلية اختيرت من محافظات القليوبية والبحيرة والثرقية. وقد أظهرت النتائج أن ذكور

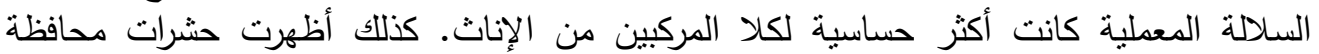

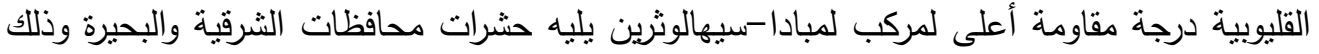

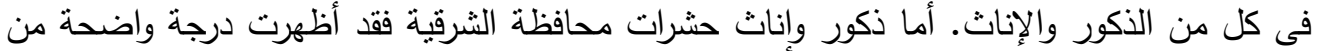

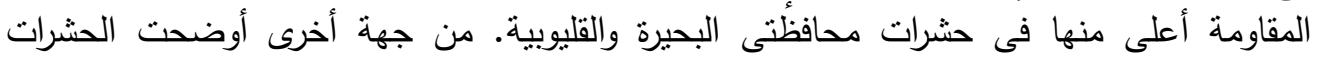

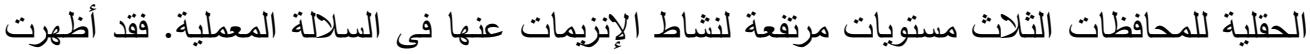

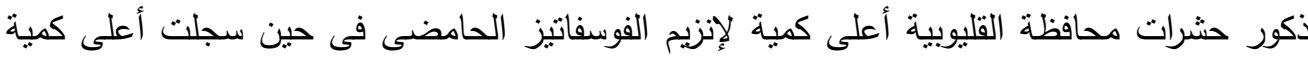

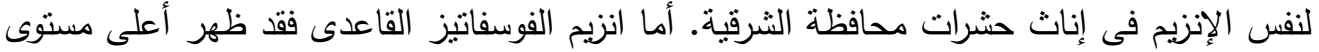

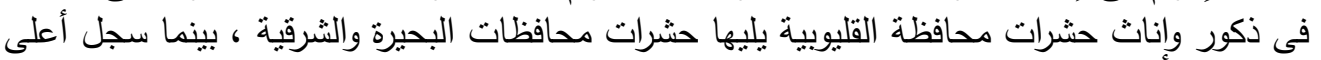

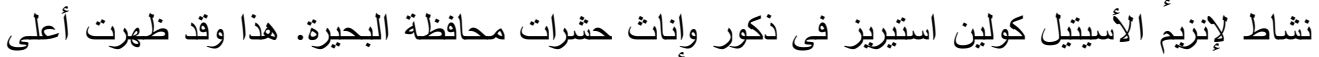

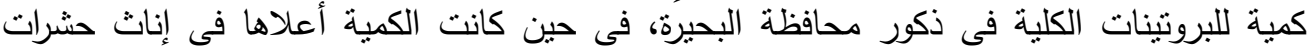

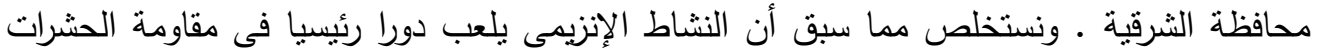

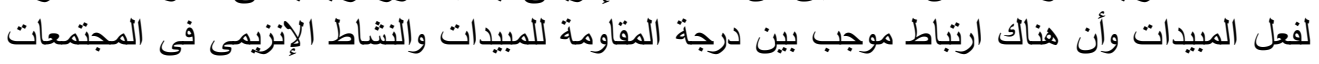

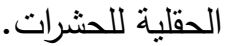
الكلمات المفتاحية: ذبابة فاكهة البحر المنتسط، الاسم العلمى لذبابة فاكهة البحر المتوسط، المبيدات

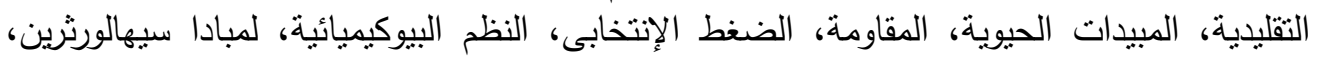

